\section{Esophageal vasculitis in granulomatosis with polyangiitis}

\section{Introduction}

Granulomatosis with polyangiitis (GPA; formerly Wegener's granulomatosis) affects the gastrointestinal tract infrequently as compared to other small or medium vessel vasculitis. Case reports of lower gastrointestinal (GI) involvement in GPA are numerous but esophageal vasculitis due to GPA is extremely rare. Only six cases of esophageal involvement in GPA have been reported in the literature thus far. We present the diagnostic and treatment challenges in a case of esophageal ulceration due to GPA and review the relevant literature.

\section{Case report}

A 56-year old Asian woman was referred to the Nephrology outpatient services for evaluation of renal impairment. She gave history of dysphagia for the preceding one year, which was slowly progressive and more for solids than liquids. There was associated regurgitation of gastric contents, post-prandial fullness and reflux symptoms. She also reported recurrent, itchy, painless purpuric lesions over the lower limbs for the past 2 months, along with ulcers over both ankles and blisters over the hands and feet. She gave a history of recurrent painless oral ulcers, loss of weight of $7 \mathrm{~kg}$ over the past 3 months, loss of appetite and arthralgia mainly involving the large joints. She experienced an episode of severe upper abdominal pain a month before presentation, associated with 10 to 12 episodes of increased bowel movements with altered blood, which was managed conservatively. She had occasional diffuse, poorly localized abdominal pain, with no particular relation to food. She did not have any symptoms associated with the genitourinary system. Her baseline serum creatinine a month before presentation was $0.9 \mathrm{mg} / \mathrm{dL}$. She was treated elsewhere for bilateral episcleritis 8 months previously with topical and oral steroids. She had since been intermittently on oral steroids. She did not give history of any addiction.

On examination, she looked unwell, blood pressure was $120 / 80 \mathrm{~mm} \mathrm{Hg}$, pulse was 84 per minute and temperature was $36.9^{\circ} \mathrm{C}$. She had palpable purpura over the trunk and extremities. Necrotic ulcers $4 \mathrm{~cm} \times 4 \mathrm{~cm}$ were present over both lateral malleoli and a smaller $2 \mathrm{~cm} \times 2 \mathrm{~cm}$ ulcer over the lateral aspect of the left leg. Examination of the oral cavity revealed three lingual ulcers ranging from 1 to $2 \mathrm{~cm}$ with raised edges and necrotic centers. Blood investigations showed a white blood cell count of $12.9 \times 10^{3}$ cells per cumm, hemoglobin of $9.6 \mathrm{~g} / \mathrm{dL}$, platelet count of $4.62 \times 10^{5}$ cells per cumm, ESR $40 \mathrm{~mm}$ at one hour, serum creatinine $2.1 \mathrm{mg} / \mathrm{dL}$, estimated glomerular filtration rate (eGFR) of $25.8 \mathrm{ml} / \mathrm{min} / 1.73 \mathrm{~m}^{2}$, normal liver function tests, negative serology for anti-nuclear antibody (ANA), topoisomerase 1 ( $\mathrm{Scl} 70)$, anti-ribonucleo protein (anti-RNP), anti-centromere antibodies (CENP), anti- Jo 1, absence of serum cryoglobulins, normal C3, C4 complements, rheumatoid factor titre of $141 \mathrm{IU} / \mathrm{Ml}$, negative hepatitis B surface antigen and hepatitis $\mathrm{C}$ antibody levels. Anti-neutrophilic cytoplasmic antibody was positive for cytoplasmic ANCA (c-ANCA) at $300 \mathrm{U}$. Urine analysis showed dipstick protein of 1+, 20-25 urine RBCs per high power field and 4-6 urine WBCs per high power field. 24-hour urine protein was $448 \mathrm{mg}$. Barium swallow revealed persistent luminal narrowing with mucosal irregularity of the distal third of the esophagus and significant gastroesophageal reflux. Upper GI endoscopy revealed diffuse circumferential lower esophageal ulceration, with significant luminal narrowing preventing further intubation (Figure 1). Esophageal biopsy showed extensive ulceration, with no evidence of dysplasia or malignancy. ARyle's tube was placed over a guidewire under fluoroscopy. Biopsy of the tongue ulcer showed epithelial hyperplasia and ulceration, with no evidence of malignancy. Punch biopsy of the skin showed evidence of leucocytoclastic vasculitis. Renal biopsy was reported as pauci immune focal segmental proliferative and sclerosing glomerulonephritis.

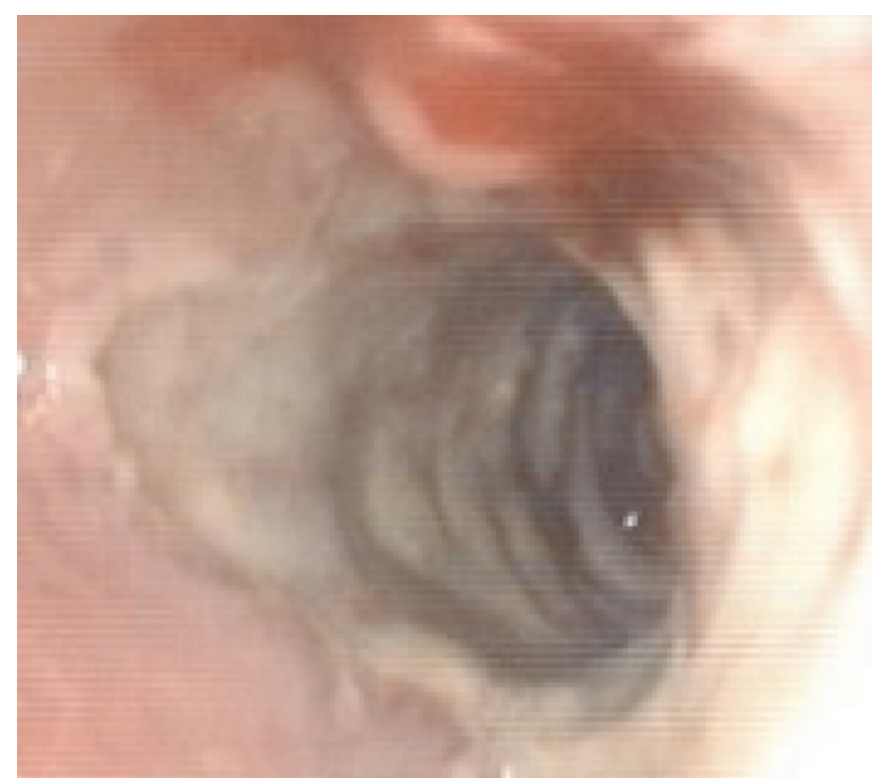

Figure 1: Upper GI endoscopy showing diffuse circumferential esophageal ulceration. 


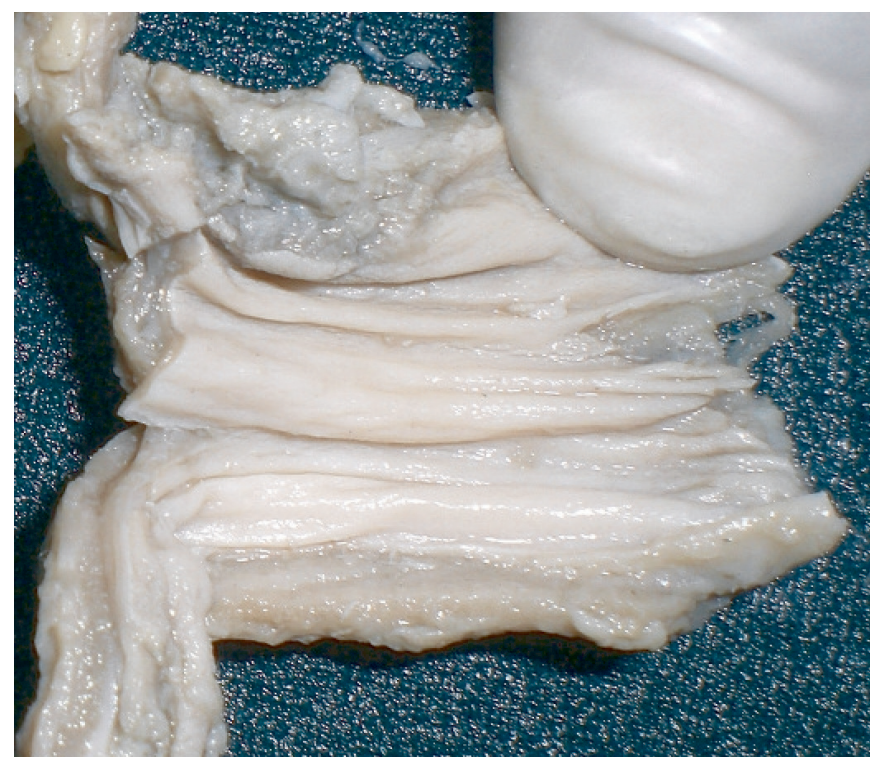

Figure 2: Gross specimen of postmortem esophagus with ulceration and granular appearance of the mucosa.

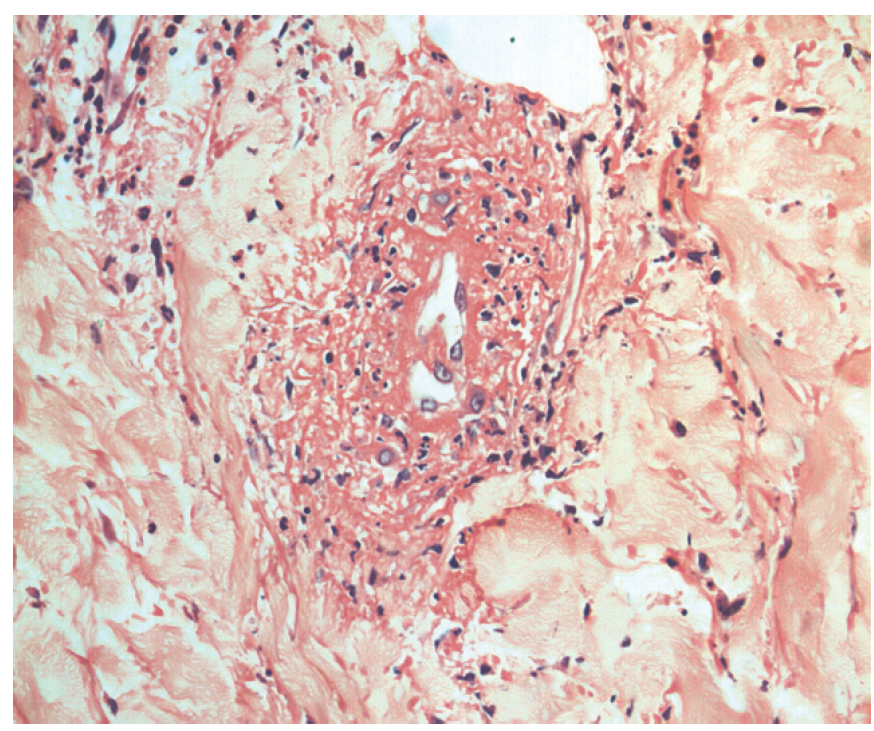

Figure 3: Section from postmortem esophagus showing leucocytoclastic vasculitis of a submucosal blood vessel, H\&E 400x.

The patient satisfied the American College of Rheumatology criteria for GPA and fulfilled the definition of GPA in the Chapel Hill Consensus Conference. She received intravenous pulses of methylprednisolone for three consecutive days, but succumbed to sudden massive pulmonary hemorrhage a day after completing the pulse therapy. Autopsy was performed with consent of next of kin. Gross and microscopic examination confirmed the cause of death as massive pulmonary haemorrhage. The esophageal mucosa at the lower one third was granular and ulcerated (Figure 2), and showed transmural inflammation comprising of neutrophils, lymphocytes and histiocytes with fibrosis of lamina propria. There was evidence of leucocytoclastic vasculitis with fibrinoid necrosis of the vessel walls (Figure 3). There were two incidentally detected perforations $1.5 \mathrm{~cm}$ and $1.0 \mathrm{~cm}$ in diameter about $150 \mathrm{~cm}$ from the ileocaecal valve. The small intestinal wall near the perforation also had necrotic debris, acute fibrinous exudates and transmural infiltrates of neutrophils and monocytes. Histology of the kidney was consistent with the renal biopsy findings.

The differentials for these ulcerative lesions in the esophagus also include infective causes like Candida and Cytomegalovirus (CMV). On endoscopy, there were no curdy white precipitates suggestive of candida. The gross specimen of the esophagus on autopsy did not show any features of Candida (Figure 2). There was no evidence of Candida or CMV inclusions on histopathology.

\section{Discussion}

The first two cases of GPA on record were those of Klinger (1931) and Rossle (1933), but it was Friedrich Wegener (1936, 1939) who first described the disease in detail, and hence the name "Wegener's granulomatosis" (WG). Recently it has been renamed as "granulomatosis with polyangiitis (GPA)". ${ }^{1}$ The pathological features of GPA were defined by Godman and Churg (1954), with a diagnostic triad of necrotizing granulomas of upper and lower respiratory tract, panvasculitis and focal glomerulonephritis, but these were largely based on autopsy studies. ${ }^{2}$ Limited forms of GPA, with no renal involvement, and increased patient survival, were first described by Carrington and Liebow in 1966. Fauci et al, in their series of 85 patients with GPA proposed that the diagnosis requires clinical involvement in two of three sites (upper airways, lungs and kidney) along with histological confirmation in preferably two sites, though one site may suffice.

Gastrointestinal vasculitis does not generally occur in isolation, and is associated more frequently with polyarteritis nodosa, Churg-Strauss or microscopic polyangitis rather than GPA, ${ }^{3}$ and is reported in about $5-11 \%$ of cases. The symptoms are mostly loss of appetite, pain, diarrhea or hematochezia. Esophageal involvement has been described only in six previous case reports of GPA, 4,5 with one being an asymptomatic esophageal arteritis found during autopsy study. Upper GI endoscopy is helpful in defining the extent of involvement. Out of the seven case reports (including ours), six had endoscopic evaluation. Esophageal ulcerations were discrete and punched out in four of these reports. Diffuse 
circumferential esophageal ulcerations were present in the other two case reports (including ours), and could represent an advanced disease state as these patients died of disease complications despite immunosuppression. ${ }^{4}$ Endoscopic biopsies were nonspecific and not diagnostic in four out of the six cases (including ours). It has been suggested that endoscopic biopsies are superficial and may not be diagnostic. ${ }^{3}$ Interestingly, in four of these reports (including ours), dysphagia was the prominent symptom. Esophageal involvement can also be the presenting symptom of GPA as seen in our case.

Physicians need to be aware of GPA as a cause of esophageal ulcers, to prevent delay in diagnosis and treatment. In the present case, the decision to administer high dose steroids had to be weighed against the risk of precipitating GI hemorrhage. Management of such cases is essentially high dose immunosuppression, as generally used in the induction phase of vasculitis. Esophageal strictures may require serial dilatation. ${ }^{5}$ This report highlights esophageal involvement as a rare presentation of GPA.

SUCEENA ALEXANDER ${ }^{1}$, EBBY GEORGE SIMON², DEEPAK BURAD ${ }^{3}$, SANTOSH VARUGHESE ${ }^{1}$, VINOI GEORGE DAVID ${ }^{1}$, SHIBU JACOB ${ }^{1}$, GOLLA SUDHAKAR ${ }^{1}$ VEERASAMY TAMILARASI ${ }^{1}$, CHAKKO KORULA JACOB ${ }^{1}$, CHARLES D PUSEY ${ }^{4}$,

Correspondence: Dr. Suceena Alexander, Department of Nephrology', Gastroenterology ${ }^{2}$, General Pathology, Christian Medical College, Vellore, India and Department of Medicine 4 , Imperial College, London Email:suceena@gmail.com

\section{References}

1. Falk RJ, Gross WL, Guillevin L, Hoffman GS, Jayne DR, Jennette JC, et al. Granulomatosis with Polyangiitis (Wegener's): An alternative name for Wegener's Granulomatosis. Arthritis Rheum. 2011;63:863-4.

2. Godman GC, Churg J. Wegener's granulomatosis: pathology and review of the literature. AMA Arch Pathol. 1954;58:533-53.

3. Camilleri M, Pusey CD, Chadwick VS, Rees AJ. Gastrointestinal manifestations of systemic vasculitis. $Q$ J Med. 1983;52:141-9.
4. Fallows GA, Hamilton SF, Taylor DS, Reddy SB. Esophageal involvement in Wegener's granulomatosis: a case report and review of the literature. Can J Gastroenterol. 2000;14:449-51.

5. Reddy RS, Biyyani S, Pauskar P, Fahmy NM, King JF. Extensive gastrointestinal tract and thyroid involvement with Wegeners granulomatosis. Indian J Gastroenterol. 2007;26:290-1.

\section{Non communicating gastric antral duplication cyst presenting with hematemesis due to large antral ulcer}

\section{Introduction}

Gastrointestinal duplications are congenital anomalies due to defective canalization of the GI tract. They may occur at any site from mouth to anus, but with variable frequency. ${ }^{1}$ Gastric duplications are among the relatively rare duplications, and are usually difficult to diagnose and treat. We report here a case of gastric duplication, which presented as a large antral gastric ulcer with hematemesis.

Case: A 7-year old boy came to us with a history of periumbilical and epigastric pain abdomen, which started 2 years prior to presentation, and lasted for 6 months, and was being managed with proton pump inhibitors. There was no history of

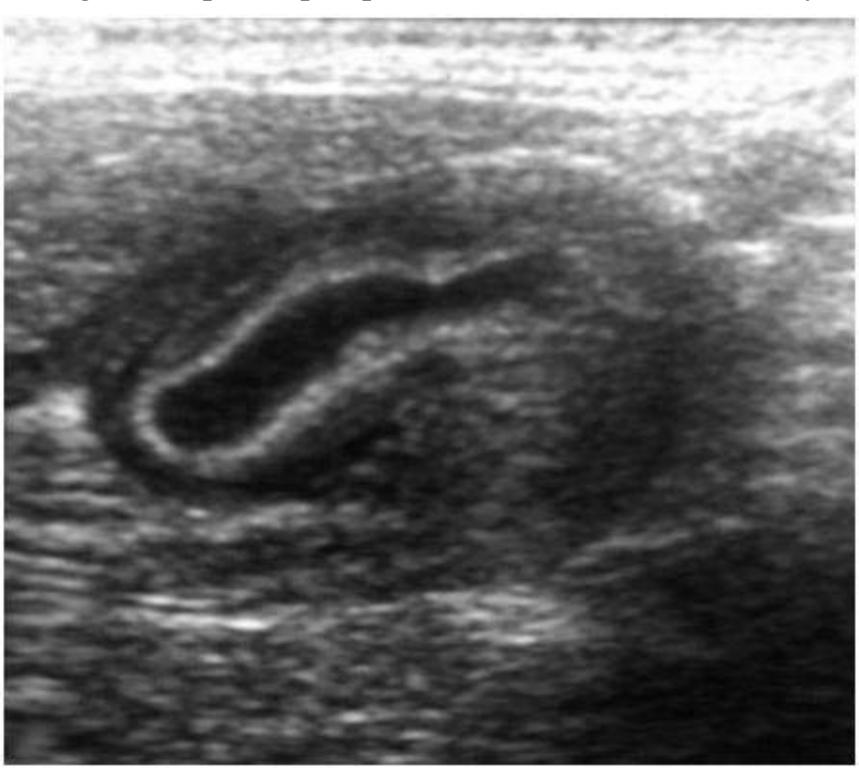

Figure 1: USG showing duplication cyst (Typical gut signature) 